\title{
A study of water infiltration basin and clogging using column experiments
}

\author{
Elyasse El Mrabet ${ }^{1}$, Lhoussaine El Mezouary ${ }^{2}$, Bouabid El Mansouri ${ }^{1}$ \\ ${ }^{1}$ Laboratory of hydroinformatics, Faculty of Sciences, University Ibn Tofail, Campus Maamora, BP. 1331400 Kenitra, Morocco. \\ ${ }^{2}$ Laboratories of mathematical and analysis, noncommutative geometry and applications, Faculty of Science, Ibn Tofail University, \\ Campus Maamora, BP.133, 1400 Kénitra, Maroc.
}

\begin{abstract}
The clogging of infiltration basins is the main problem affecting the proper functioning of groundwater artificial recharge systems. In this study, several parameters have been varied to understand their impacts on water infiltration. The experimental results show that the effect of initial humidity is significant for less porous material such as silty soil (Hamri) and sand. The air bubbles are also an important factor to take into consideration since when trapped within porous structures, it forms a barrier for the displacement of water infiltration. The accumulation of suspended particles in stormwater can contribute to clogging by creating a light layer due to the finest particles, which remain in suspension for a long time. Finally, for the tested materials and experimental conditions, we observed that a combination of a silty soil and sand layer in the design of infiltration basins was more practical than a combination of sand and gravel. The latter, despite its high porosity, could release very fine particles; which would create a cement layer of clogging when deposited at the interface. This layer is an obstacle for water infiltration, thus rendering the device thus constructed unsuitably for groundwater recharge, by reducing its life.
\end{abstract}

\section{Introduction}

Infiltration basins are a good management tool for rainwater and treated wastewater. Widely used today as an alternative to the sewerage network of stormwater, which reduces the risk of flooding, contributes to the trapping of pollutants, and allows the settling of suspended matter loaded with pollutants [1-3]. Infiltration basins are also known to recharge the groundwater as well as other benefits [4-7]. Despite their beneficial characteristics, these systems are exposed in the long term by the risk of clogging, which reduces its hydraulic performance and limits the interception capabilities of water flows and pollutants.

The superficial zone of infiltration basins undergoes numerous processes over time, such as discontinuous flow of water and charged by sediments and pollutants. These intermittent bring related to rain, are characterized by various physicochemical and biological phenomena, which makes the interface structure/soil very evolving in time and heterogeneous in space, causing the clogging phenomena. Therefore, special attention should be put to the specification of the original filter media, to ensure its compliance with the design requirements [8].

In artificial recharge projects [6,9], clogging is a serious problem for the proper functioning of infiltration basins. This operation depends on the physicochemical and hydraulic properties of the underlying soil and the composition of recharge water (suspended particles, organic matter, etc.). The choice of the hydraulic structure depends on the hydraulic properties of the existing environment as well as on the technical and cost considerations. The infiltration basin is dug into the ground, and the designer has the choice to leave the natural drainage to the soil or to deposit a layer of draining materials to a certain depth (sand, gravel, or pebble, etc.).

Several studies presented the infiltration of water into basins assessment by both performing column experiments and In-situ tests to characterize the infiltration or by varying bio-physicochemical parameters related to draining soil, and the composition of recharge water. Winearski et al. [10] have studied the bio-physicochemical impacts of stormwater from a drainage basin such as $\mathrm{pH}$, organic matter, particle size, and counts of viable heterotrophic bacteria. Barraud et al. [11] showed that pollutant concentrations decrease rapidly with depth while increasing $\mathrm{pH}$ and grain size. We can observe a significant influence of the organic matter (composition and mode of accumulation) and the fine particles that migrate to depth, and influence the distribution of the pores and thus cause the clogging [12, 13]. The decrease in infiltration rate, as well as the depth and the hydraulic effect of clogging, were evaluated for a sandy infiltration basin containing 51 and $61 \mathrm{mg} / 1$ of suspended matter [14]. Siriwardene et al. [15] have also studied physical clogging. The study showed the formation of a layer at the interface between the filter and the underlying soil found, irrespective of the entry regime of water and sediments. Clogging occurs more slowly if the water level is maintained at a constant level than if it varies in the column, due to the formation of a sediment plug that protects the filter/soil interface. Siriwardene concludes that physical clogging is mainly due to the migration of sediment particles less than $6 \mu \mathrm{m}$ 
in diameter. Continuing with rainwater charged particles, it has been found that colloids also play a very important role in transporting pollutants and metal towards significant depths. Durin et al. [16] have proved the role of the basin in attenuating changes in physicochemical parameters and chemical element concentrations. Another factor that can influence water infiltration is sediment settlement. The latter can reduce the water infiltration capacity, due to their lower saturated hydraulic conductivity, which has been confirmed by Lassabatere et al. [17]. Le Coustumer et al. [18] studied the evolution of hydraulic conductivity over time concerning many parameters such as the depth of the filter, type of vegetation, size of the system. The choice of plant species appears significant on the rate of decrease in permeability. He also found that small recharge basins that are subject to high recharge rates become clogged more easily, as increased hydraulic head and sediments results in extremely low hydraulic conductivity.

To study the capacity of these water-infiltration basins and the different influencing parameters, In-situ studies sometimes seem complicated to carry out because of the time required for wet seasons, where the inflow of rainwater is important, besides monitoring of some physicochemical parameters according to the needs of the studies. Thus, for designers before setting up such a project and embarking on such an investment, it was essential before implementing this type of study to perform controlled column experiments, by varying several parameters such as the type material to be used, and some physicochemical parameters influencing infiltration.

In this study, we will carry out columnar water injection experiments for three types of materials (silty soil, sand, and gravel), by varying several parameters such as the effect of material type, humidity, turbidity, air bubbles, and superposition of two material layers on the water infiltration velocity.

\section{Materials And Methodology}

\subsection{Experimental Device}

The experimental device used for the column experiments carried out in this study consists of a rigid transparent plastic column, approximately $25 \mathrm{~cm}$ long, and with a diameter of $10 \mathrm{~cm}$ (Fig.1). The device is composed of an opening at the outlet glued with a filter. This filter with openings of $2 \mathrm{~mm}$ in diameter allows the water to flow without permitting the particles of the material's porous media.

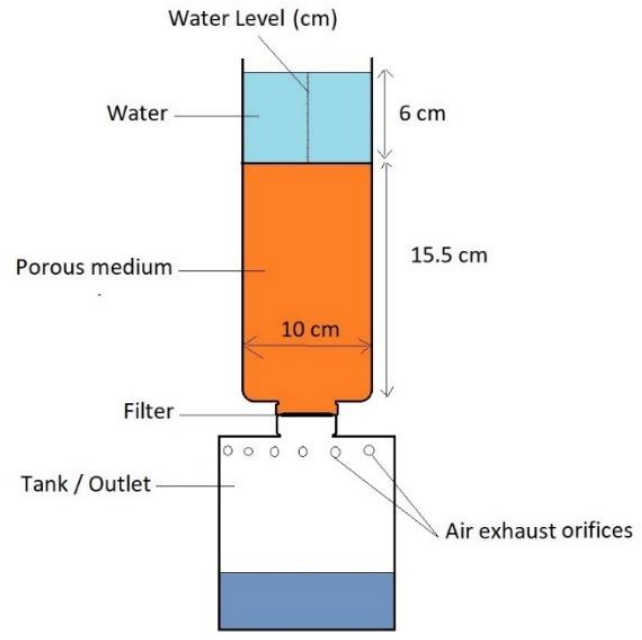

Fig. 1. Experimental device

The outlet of the column is connected separately into two types of tanks. The first tank with openings on the sides, and allow the escape of bubble air trapped in the tube, pushed by the infiltration front. The second tank without openings, to prevent any escape of air bubbles during the infiltration, trapped in the column.

\subsection{Type of materials}

We selected three different types of materials for this experiment and those were characterized by different textures. The first material represents the local silty soil of Northwestern of Morocco called "Hamri" (Fig. 2-a).

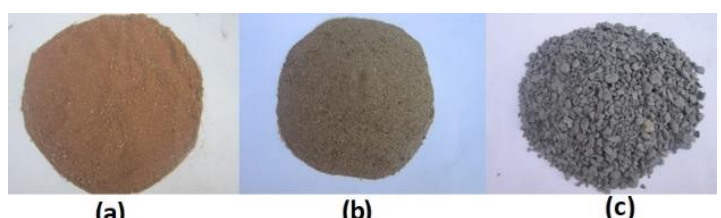

(a) (b)

(c)

Fig. 2. Type of soil: (a)-Silty Soil (Hamri), (b)-Sand, (c)Gravel

The red coloration by iron is very marked on these soils rich in sesquioxides, the alteration is neutral hydrolysis or low acid, whence the conservation of the released hydroxides rich in $\mathrm{Fe}$ and $\mathrm{Al}$.

The second type of soil tested in this study (Fig. 2-b), corresponds to the beach sand of the coastal strip of northern Morocco. This sand type is widely used in construction. The third type of material considered in this study (Fig. 2-c), is the industrial gravel used in construction These aggregates are characterized by granular particles of resizable stone material. They are formed naturally through the fragmentation of different rocks of the earth's crust. Artificially, the crushing or grinding process is the most common. The treated material mainly consists of limestone, granite, dolomite, basalt, sandstone, quartz, and quartzite

Tab. 1 gives the results of the Physico-chemical analysis of the samples of each one.

\begin{tabular}{|c|c|c|c|}
\hline Material & $\begin{array}{c}\text { Local } \\
\text { soil } \\
\text { Hamri }\end{array}$ & $\begin{array}{c}\text { San } \\
\text { d }\end{array}$ & $\begin{array}{c}\text { Grav } \\
\text { el }\end{array}$ \\
\hline
\end{tabular}




\begin{tabular}{|c|c|c|c|}
\hline $\mathrm{pH}$ & 8,1 & 8,40 & 8,60 \\
\hline $\begin{array}{c}\text { Electrical conductivity of extracts } \\
1 / 5(\mathrm{dS} / \mathrm{m})\end{array}$ & 0,18 & 0,09 & 1,60 \\
\hline Total Limestone (\%) & 40,9 & $\begin{array}{c}40,9 \\
0\end{array}$ & 84,00 \\
\hline Organic matter (\%) & 4,51 & 1,99 & 0,97 \\
\hline Organic Carbon (\%) & 2,61 & 1,16 & 0,42 \\
\hline Ammoniacal Azote (ppm) & 59,04 & $\begin{array}{c}40,3 \\
2\end{array}$ & 21,60 \\
\hline Nitric Azote (ppm) & 99,2 & $\begin{array}{c}117, \\
00\end{array}$ & 78,00 \\
\hline Mineral Azote (ppm) & 158,2 & $\begin{array}{c}157, \\
3\end{array}$ & 99,6 \\
\hline Available Phosphor (ppm) & 271 & 27,6 & 31,6 \\
\hline Exchangeable Potassium (ppm) & 182 & - & 63 \\
\hline Granulometry (\%) & & & \\
\hline Clay & & & \\
\hline Fine Silt & 5,2 & 2,60 & 0,50 \\
\hline Coarse Silt & 2,6 & 2,70 & 0,71 \\
\hline Fine Sand & 2,6 & 2,62 & 0,29 \\
\hline Coarse sand & 32,34 & $\begin{array}{c}25,4 \\
6\end{array}$ & 78,00 \\
\hline & 57,82 & 66,8 & 20,50 \\
\hline
\end{tabular}

\subsection{Experimental Procedure}

The used water column tube is composed of two filling parts without separation. The first part is filled with the material to be studied (sandy soil, silty soil, gravel, and the superposition of two types of materials). The second part is filled with a proper water volume of 0.5 liters or with turbid water, whose graduation is in centimeters. The method used consists of injecting a determined volume of water and monitoring the evolution (infiltration) of the water level.

For each experiment, we measured the water level variation as a function of time, varying several parameters, such as the type of materials, effect of humidity, the effect of air bubbles in the porous media, turbidity, and layer overlap of different materials. Finally, the results were exploited by plotting several curves. The different results infiltration water was analyzed and interpreted in the results and discussions section.

\section{Results and discussions}

\subsection{Effect of the type of drainage materials:}

We conducted three water infiltration experiments $(\mathrm{V}=$ 0.5 liter), whose column is $6 \mathrm{~cm}$ in height, each test with a different type of material: gravel, sand, and silty soil (Hamri).

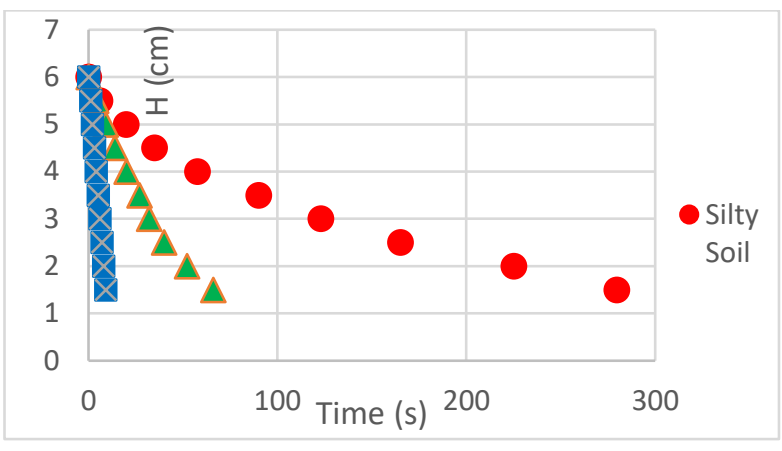

Fig. 3. Effect of the type of drainage material

As shown in Fig. 3, the infiltration of water into the gravel is quite fast $(0.5 \mathrm{~L}$ in a few seconds) because of the high porosity with a linear infiltration curve. While for the silty soil (Hamri) the waterfront takes a relatively long time to advance, and it is only after about 1 minute that the infiltration rate slows down and the curve tends to stabilize towards a constant level. The sand has medium porosity, and the infiltration front displacement takes an intermediate value between silty soil and gravel; these results are quite predictable and obvious for the three materials.

\subsection{The humidity effect of both types of materials/Effect of humidity on materials}

To study the effect of humidity on the infiltration rate of each material, we carried out several infiltration experiments for silty soil and sand, with a volume of 0.5 1. The results are presented in Fig. 4. We neglected the gravel representation in this test because of its high porosity and high hydraulic conductivity, which gives almost the same rate of infiltration between wet and dry cases.

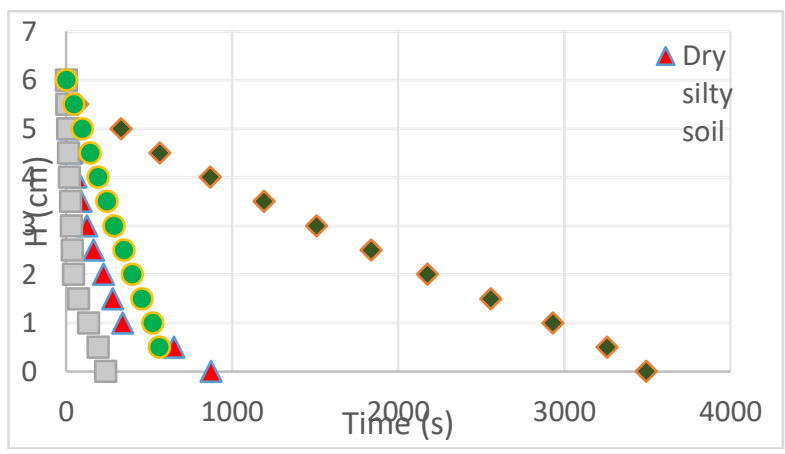

Fig. 4. The effect of humidity on both types of soil

The initial humidity of the soil type could have a significant effect on the velocity of the infiltration front. This factor seems to have no significant influence on the sand in terms of infiltration rate, while for the silty soil a large gap is seen. We can also notice that for the two materials, in the dry case, the infiltration is faster with a rate, which tends towards a constant, whereas for the wet case, it is almost constant but slower than the dry case. 


\subsection{Effect of air bubbles trapped in the porous structure of the soil}

In aquifers, air bubbles trapped inside soil and subsoil structures can contribute to a decrease in infiltration rate. In this experiment, we carried out two water infiltration experiments in the soil to evaluate the importance of this parameter. The material used in this experiment is silty soil (Hamri).

The first is to infiltrate a quantity of water $(0.51)$ in the experimental column, but with a reservoir downstream to the outlet, which contains orifices to allow the escapement of air bubbles trapped by in the pores of the material, and pushed by displacement of the infiltration front towards the outlet.

The second experiment consists of the infiltration of the same quantity of water in the column, using a reservoir at the outlet to prevent any escape of air bubbles; the results are displayed in the following Fig. 5:

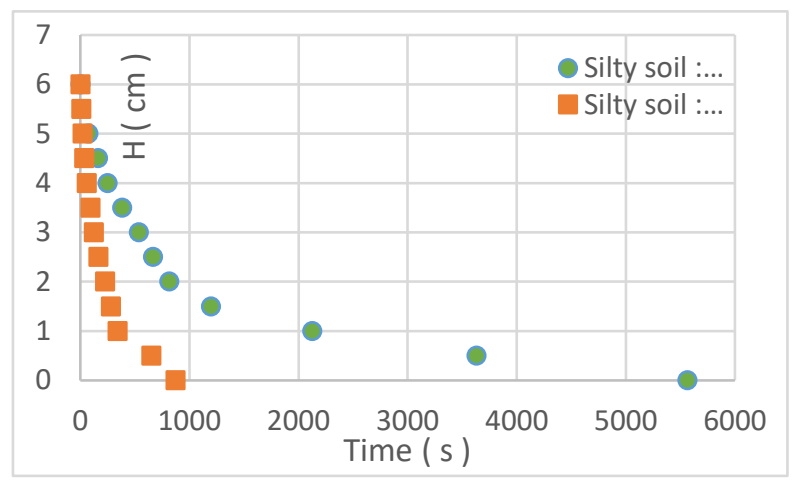

Fig. 5. Effect of trapped air bubbles in the vadose zone

The results of the experiment show that for the open orifices of the porous medium, infiltration of the total quantity of water took 15 minutes. However, for the closed orifices, the infiltration of the same water quantity lasted one hour and a half (about 6 times the longer than the case of open soil). This shows that air bubbles trapped in the unsaturated zone could be a significant slowing factor of the infiltration rate of water into the soil.

\subsection{Turbidity water effect/Effect of turbidity}

To study the effect of turbidity (water charged with small particles of silty soil at a density of $3 \mathrm{~g} / \mathrm{L}$ ), we carried out a series of infiltration of water only (a faucet clean water IC1), then on wet sand charged with particles (IC2 and IC3), without change of materials in the column. Between the three injections (IC1, IC2, IC3), there is a time interval of 24 hours, to simulate in which case a rain event for water charged with particles.

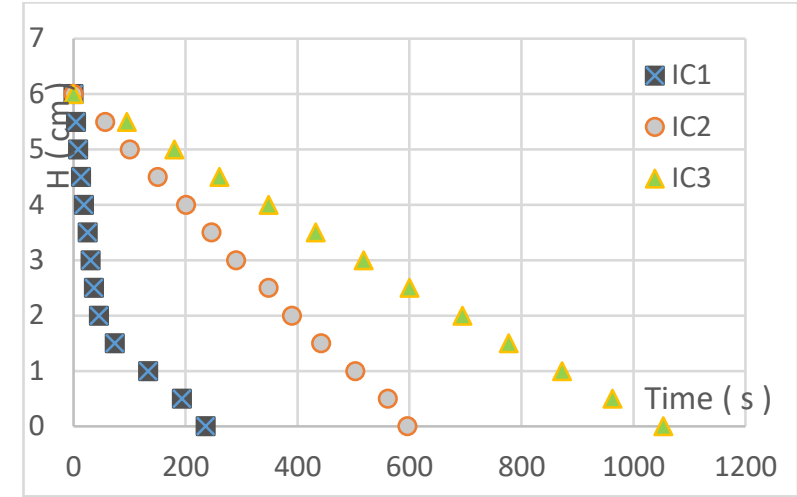

Fig. 6. Effect of water turbidity

According to Fig. 6, turbid water slows the advance of the infiltration front. The first curve (IC1) represents an infiltration on dry soil, which accelerated at the beginning and tends to stabilize. For IC2, IC3 represents an infiltration on wet sand materiel, with water charged of particles (density $3 \mathrm{~g} / \mathrm{L}$ ). In the last case, the infiltration is relatively slower and tends to slow down with each addition of turbid water.

We observe at the end of the experiment, the appearance of two very thin layers above the sand layer of less than one millimeter. A first layer is formed of sand grains of turbid water with coarse particles and a second layer with very fine particles. The largest particles are deposited first, followed by very fine particles in suspension, and slowly drowning the second layer, which could be the main factor in clogging.

However, despite these results, we cannot confirm for this test, the effect of this parameter on the decrease of infiltration, because as it was found previously (Fig. 5), the initial humidity can contribute to the decrease of the infiltration. As a result, the turbidity of particle-laden water accentuates the clogging through the deposition of a thin layer with very low conductivity.

\subsection{Effect of soil-sand, soil-gravel overlay}

To simulate the design of a stormwater infiltration system concerning the type of drainage material, that could be combined with the natural soil for infiltration. We performed two experiments using two superimposed layers; the first layer of silty soil at the bottom, and sand at the top, the second layer of silty soil at the bottom, and gravel at the top (Fig. 7). 


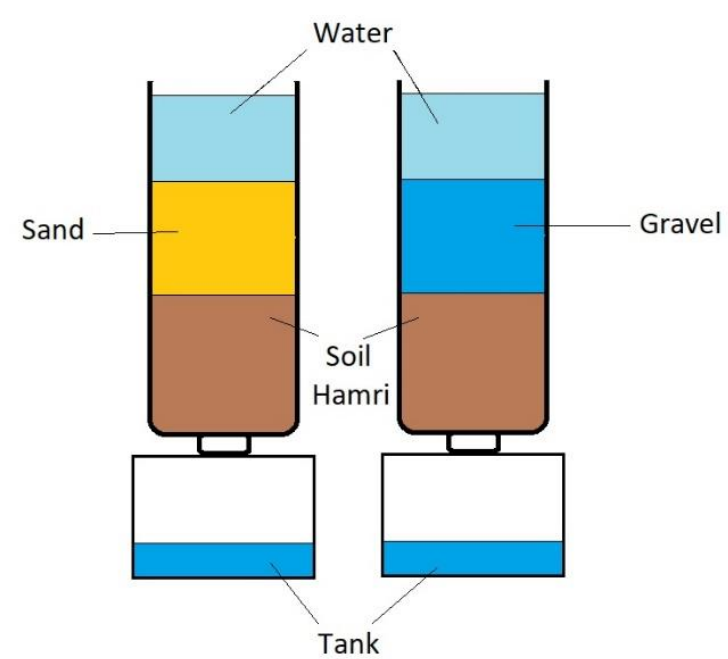

Fig. 7. Descriptive diagram of the overlay of different materials types

An infiltration experience test in the column was realized, and we recorded the following results shown in Fig. 8:

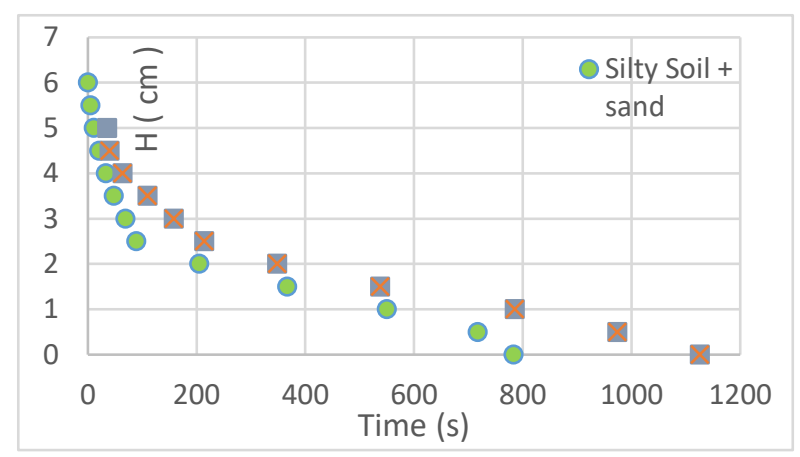

Fig. 8. Effect of silty soil-sand, silty soil-gravel overlay.

Figure 9 shows that water infiltrates more quickly in the layer formed by sandy + silty soil than the layer formed by silty soil + gravel.

The result appears contradictory with the other previous results (Fig. 4), which reveal that the water infiltrates more quickly with the gravel. Indeed, we inspected the contact interface between the soil and the gravel, and we observed a formation of a bluish coloring layer cementing the surface, which reduced the passage of water and attenuated the infiltration. These particles of fine grains clogging the interface are the result of friction between gravel grains, and with the passage of water, these particles migrate and clog the interface, which could defeat any artificial recharge project according to this design.

\section{Conclusions}

To study the influence of several parameters likely to influence the infiltration front velocity of the basins intended for artificial recharge, we carried out some experiments in columns. These experiments consist of highlighting the infiltration of water through a column filled with a material. Three types of materials were used for these experiments: sand, gravel, and silty soil
(Hamri) to characterize the infiltration of water. We varied several parameters, such as the type of material, the effect of the initial humidity of the material, air bubbles of the unsaturated zone, turbidity, and finally the effect of overlapping two types of materials with the silty soil.

Experimental results show that for sand and silty soil materiel, that initial humidity is an influencing factor on the infiltration water velocity. In addition, the effect of the air bubble is significant, because that remains trapped in the porous structures, and which represents a pressure barrier to the movement of the front water infiltration. Accumulation of suspended particles in stormwater can contribute to the clogging by creating a light layer due to the finest particles, which remain in suspension the most time, slowly deposited.

Finally, and relative to the type of gravel tested in this study, a combination of a silty soil + sand layer in the design of infiltration basins is more practical than a combination of silty soil + gravel layer because the latter and despite the high porosity, can release very fine particles that settle at the interface creating a layer of clogging cement mitigating the infiltration of water and decreases the life of the basin. Therefore, a special intention must be made on the physical and chemical properties of the type of artificial material used for drainage.

\section{References}

1. Bechet, B., et al. Rôle des bassins de rétentioninfiltration dans l'épuration des eaux de ruissellement péri-urbaines. in 11ème congrés de la Société Française de Génie des Procédés (SFGP 2007). 2007.

2. El Mezouary, L., et al., Modélisation numérique de la variation saisonnière de la qualité des eaux souterraines de l'aquifère de Magra, Italie. 2015(2): p. 25-31.

3. El Mezouary, L., et al. Coupling of numerical flow model with the Susceptibility Index method (SI) to assess the groundwater vulnerability to pollution. in Proceedings of the 4th Edition of International Conference on Geo-IT and Water Resources 2020, Geo-IT and Water Resources 2020. 2020.

4. Bouwer, H.J.H.j., Artificial recharge of groundwater: hydrogeology and engineering. 2002. 10(1): p. 121-142.

5. Bouwer, H.J.W.S. and Technology, Issues in artificial recharge. 1996. 33(10-11): p. 381-390.

6. Sadiki, M.L., et al., Improvement of groundwater resources potential by artificial recharge technique: a case study of charf el Akab aquifer in the Tangier region, Morocco. 2019. 7(3): p. 224236.

7. Draoui, Y., et al., Quantification of Surface WaterGroundwater Exchanges by GIS Coupled with Experimental Gauging in an Alluvial Environment.

8. Le Coustumer, S., et al., Hydraulic performance of biofilter systems for stormwater management: 
Influences of design and operation. 2009. 376(12): p. 16-23.

9. El Mansouri, B. and L.J.P.o.t.I.A.o.H.S. El Mezouary, Enhancement of groundwater potential by aquifer artificial recharge techniques: an adaptation to climate change. 2015. 366: p. 155156.

10. Winiarski, T., et al., The impact of stormwater on a soil profile in an infiltration basin. 2006. 14(7): p. 1244-1251.

11. Barraud, S., et al., Statistical analysis of pollution in stormwater infiltration basins. 2005. 51(2): p. 19.

12. Cannavo, P., et al., Spatial distribution of sediments and transfer properties in soils in a stormwater infiltration basin. 2010. 10(8): p. 14991509.

13. Zhao, Y., et al., Water quality forecast through application of BP neural network at Yuqiao reservoir. 2007. 8(9): p. 1482-1487.

14. Schuh, W.M.J.J.o.H., Seasonal variation of clogging of an artificial recharge basin in a northern climate. 1990. 121(1-4): p. 193-215.

15. Siriwardene, N.R., A. Deletic, and T.J.W.r. Fletcher, Clogging of stormwater gravel infiltration systems and filters: Insights from a laboratory study. 2007. 41(7): p. 1433-1440.

16. Durin, B., et al., Role of colloids in heavy metal transfer through a retention-infiltration basin. 2007. 56(11): p. 91-99.

17. Lassabatere, L., et al., Effect of the settlement of sediments on water infiltration in two urban infiltration basins. 2010. 156(3-4): p. 316-325.

18. Le Coustumer, S., et al., The influence of design parameters on clogging of stormwater biofilters: A large-scale column study. 2012. 46(20): p. 67436752 . 